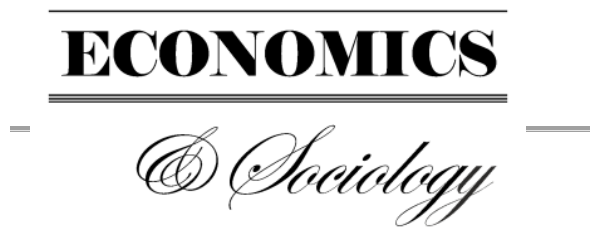

Stankevičienė, J., Maditinos, D. I., \& Kraujalienè, L. (2019). MULTIMOORA as the instrument to evaluate the technology transfer process in higher education institutions. Economics and Sociology, 12(2), 345-360. doi:10.14254/2071-

789X.2019/12-2/21

\title{
MULTIMOORA AS THE INSTRUMENT TO EVALUATE THE TECHNOLOGY TRANSFER PROCESS IN HIGHER EDUCATION INSTITUTIONS
}

Jelena Stankevičienè, Vilnius Gediminas Technical

University,

Vilnius, Lithuania,

E-mail:

jelena.stankeviciene@vgtu.lt

ORCID 0000-0002-5600-5842

Dimitrios I. Maditinos,

Eastern Macedonia \& Thrace

Institute of Technology,

Kavala, Greece,

E-mail:dmadi@teikav.edu.gr

ORCID 0000-0002-9174-3074

Lidija Kraujalienè,

Vilnius Gediminas Technical

University,

Vilnius, Lithuania,

E-mail:lidija.kraujaliene@vgtu.lt

ORCID 0000-0002-8769-8338

Received: January, 2019

1st Revision: March, 2019

Accepted: May, 2019

DOI: $10.14254 / 2071-$

789X.2019/12-2/21

JEL Classification: G32, O32, O34.

\begin{abstract}
This paper is presenting the model to assess the technology transfer (T'T) process economic performance of universities. The main indicators were identified and empirical research with MULTIMOORA tool was performed on 7 Lithuanian state-funded universities. The data was gathered from the Research Council of Lithuania official public report for the period of [2012-2014]. The research results show that MULTIMOORA tool fits to evaluate the TT process economic performance of HEIs. The proposed model is applicable to assess different results of T'T process activities in HEIs. MULTIMOORA is a multi-criteria non-subjective evaluation tool, allowing to increase the choices of alternatives and features, serving to select the best alternatives, moreover, enabling more efficient allocation of financial and human resources. MULTIMOORA tool allows extending the implementation onto other countries.
\end{abstract}

Keywords: technology transfer (TT) process, performance, MULTIMOORA, evaluation, higher education institutions (HEI), university.

\section{Introduction}

Both scholars and practitioners recognize the fact that efficient technology transfer (TT) process is crucially important in enhancing economic development of a country (De Beer et al., 2017). TT is a process occurring between two or more entities; it consists in the flow of knowledge of technological content in diverse ways including products, licenses, research and 
development projects, technical studies and cooperation, among others. It is a complex topic, closely related to collaboration between government, academia, and industry (Miller et al., 2018). In recent years, there has been growing awareness on the need for establishing and strengthening the links between scientific and research activities of universities with the public or business sectors, so that TT could benefit all parties involved.

Numerous studies have analysed the knowledge and TT processes, commercialisation of technologies developed by research institutions and universities, where the crucial role is played by technology transfer offices (TTOs). The efficiency of the TT process is the subject of extreme significance; even more, as unsuccessful performance within universities was recognized as the problem in the sphere of knowledge and TT. In this paper, we conceptualize the performance valuation of knowledge transfer and commercialization activities.

Numerous scientific studies have explored the results and the created value of the university-industry activity in TT process, as well as how to increase the efficiency of this process in the context of science-business cooperation and knowledge commercialization (Asif \& Searcy, 2014; Sharifi, Liu, \& Ismail, 2014; Guerrero, Cunningham, 2015; Nielsen, 2015; Oehler, Höfer, \& Schalkowski, 2015; Rossi \& Rosli, 2015; Hsu, Shen, Yuan, 2015; Ab Hamid, 2015; Pastor, Serrano, \& Zaera, 2015; Cattaneo, Meoli \& Signori, 2016; Bini, Dainelli \& Giunta, 2016; Maribel Guerrero, Urbano \& Fayolle, 2016).

Development and commercialization of advanced technologies increasingly depends on the efficiency TT and technology trading systems (Baek et al., 2007). Features and structure of TT organization and implementation processes have been discussed in literature, but from the policy-making perspective mostly, however, the effects of TT policy decisions have not been modelled.

There is only scarce evidence on the role of universities' TTOs within science-business cooperation and knowledge commercialization. Knowing the drivers of TTO performance may help policymakers and university managers to reflect on their strategies, mitigate weak points and thus foster performance results. While policymakers and university managers are often quite optimistic about the impact of TTOs in fostering TT into the region, consulting firms and research institutes report such institutions in Germany to be superfluous and counterproductive (Hülsbeck, Lehmann, \& Starnecker, 2013). Private and public sectors have recognized the benefits of TT and the importance of technology entrepreneurship has been considered as the main contribution to economic development.

The most important chain linking in the course of research and development and in innovation activities within universities is the academic staff (Feng, Chen, Wang, \& Chiang, 2012). Successful TT process can be ensured by means of cooperation of scientists with TTO staff. Performance of HEI also depends on the level staff competence and organizations overall (Argote, 2000). TTOs' role inside universities is important as they pull out inventions or technologies outside laboratories walls, so that to sell them at the market. Innovation policy on TT, motivation tools and accessibility of university technologies or know-how for market players have a significant effect on the TT process performance (Decter et al., 2007). Lack of commercialization experience in Lithuanian universities, not clear formulations and differences in commercialization algorithms and TT policy eventually lead to lower results in terms of economic performance.

The paper seeks to fill this gap and to provide a practical guide for policymakers on how to measure the performance of TTOs, as well as how to manage the TT process when seeking to improve economic performance of HEIs. The framework for evaluation of HEIs' performance is constructed using the decision-making multicriteria method named MULTIMOORA. The proposed evaluation model allows calculating the science-business economic performance of different HEIs activities, measured by the indicators in different measures, and allowing to rank HEIs according to the obtained economic performance results. 
The goal is to develop and implement the model to evaluate the TT process performance based on MULTIMORA methodology, to perform empirical data analysis and rank universities according to their economic performance results. The objectives of our research are as follows: 1) to design the evaluation model for comprehensive analysis of the TT process activities in HEIs; 2) to form the database for further empirical research; 3) to evaluate the obtained results and to highlight which of Lithuanian universities demonstrate the best and the worst economic performance results in what concerns TT. The data for this research study has been taken for the period of three years [2012 - 2014], and this was official public data from the Research Council of Lithuania.

The rest of the paper is organized as follows. The next section is discussing the main theoretical considerations behind the TT process, reviewing necessary conditions and assumptions in assessing the efficiency of TTO. The methodological part describes the main principles and the potential of MULTIMORA method as an instrument for evaluation of the TT process economic performance indicators. The empirical application of the suggested model is presented in section IV. The data is also described in this section. Section V concludes the paper.

\section{Literature review}

Universities are interpreted as the key actors in the national innovation ecosystems. The TT process takes place within an increasingly complex network of stakeholders (Miller et al., 2018). Within such ecosystems, universities are playing the role of vehicles for TT as the conduit through which knowledge exchange is transferring in the more effective way (Cao, Zhao \& Chen, 2009). TTO plays a critical role as a translator between the two parties academia and industry (Franklin et al., 2001; Collier, 2007). This complexity has resulted in quadruple helix models where the triple helix model of academia, industry, and government now includes societal-based innovation users as a fourth helix (Miller et al., 2018). While TTO's objectives and organisation can vary across universities, they all share the same generic aim of facilitating and managing the disclosure and licensing of inventions with commercial promise (Siegel et al., 2003).

Resultant entities include, in addition to intellectual property (IP), licensing, patenting, spin-out companies and spin-in companies into university incubators, and other technology bridge foundations or intermediaries (Bercovitz \& Feldman, 2006), which support the codification and commercialisation of knowledge in the university context for commercialisation purposes (Rademakers, 2005).

The increasing importance placed upon the regional development and the knowledgebased economy as economic growth is leading to a changing role for universities and their interaction with the business community through the transfer of technology from academia to industry. McAdam and colleagues (2012) examined the stakeholder relationship in the context of TTO and the RDA (Regional development agency). According to obtained results, greater targeted policy and funding, based on the stakeholder relationship approach, is leading to the development of joint mechanisms and a closer alignment of performance measures between the TTO and the RDA. However, over-reliance on the unitary nature of the TTO-RDA relationship may lead to a lack of cultivation and dependency on funding from other stakeholders (McAdam et al., 2012).

Few studies (and even less relevant) can be found in the literature to specifically address the assessment of the HEIs performance of TTOs exploring the main drivers of the TTOs efficiency. The main aim of TTO is to maximize the revenues of the commercialization of academic results and to manage this process. Chapple and colleagues (2005) presented evidence on the relative performance of U.K. university TTOs, using data envelopment analysis (DEA) 
and stochastic frontier estimation (SFE). They found that there is a need to upgrade the business skills and capabilities of U.K. TTO managers and licensing officers (Chapple, Lockett, Siegel, \& Wright, 2005).

Conti \& Gaule (2011) was comparing European and US TTOs. Their analysis revealed that US TTOs do not attach more importance to generating revenue as an objective than their European counterparts. However, they employ more staff with experience in the industry, which explains some of the remaining differentials in license income performance (Conti \& Gaule, 2011).

Subsequently, Zhurakovska (2013) continued this line of analytic thinking and proposed the methodical approach regarding integrated economic monitoring of TTOs activity, involving five business activity research directions: research and development activity results within technology platforms; financing of research and development projects involved in TTO for the future introduction to manufacturing; IP protection rate secured by TTO; activity rate of TTO; and effectiveness of TTO activity, which will help to determine special features of activity of such offices within technology platforms (Zhurakovska, 2013). Hülsbeck and colleagues (2013) have analysed how variance in performance can be explained by different organizational structures and variables of TTO. Obtained results revealed that TTO performance is mainly a function of the kind of labour division within the TTO and the research intensity of the university (Hülsbeck et al., 2013). Tseng and Raudensky (2014) proposed two key performance indicators to govern the success of the university TT: overall performance metric (OPM) and patenting control ratio (PCR), which are the representing combined indicators for the TTO performance (Tseng \& Raudensky, 2014). French researchers Curi and colleagues (2015) have found an average increase in the short-term productivity of the French TTOs driven by both positive efficiency and technology change. Moreover, while older TTOs positively contribute to the performance of French TTOs in the short run, young TTOs with hospitals seem to contribute negatively to the efficiency of the entire system (Curi, Daraio, \& Llerena, 2015). Lafuente and Berbegal-Mirabent (2017) have analysed the productivity of Spanish TTOs during 2006-2011 by computing total factor productivity models rooted in non-parametric techniques, namely, the Malmquist index (Lafuente \& Berbegal-Mirabent, 2017).

Most of previous studies have taken into consideration an incomplete construct of what is conventionally regarded as a framework of the main efficiency drivers of TTO performance. The literature on TTOs focuses on the main variables explaining the performance of these organizations and considering that the TTOs have to control all activities, resources, and components of the value chain of the TT process. Siegel and colleagues (2003) have concluded that the most critical organizational factors are faculty reward systems, TTO staffing/compensation practices, and cultural barriers between universities and firms. Closs and colleagues (2012) have identified the main factors of TTOs' performance: innovation among pillars of management; valuing of research and IP; qualified students, teachers, and managers; multidisciplinary research groups; stability of governing body; and performance of the TTO, Technology Management Agency, and Technology Park (Closs, Ferreira, Soria, Sampaio, \& Perin, 2012).

According to Matt and Schaeffer (2012), in France, TTOs have developed cooperative strategies with other local TTOs, on the one hand, to pool resources and share costs, and on the other hand, to structure the regional innovation system. Instead of having the unique objective of maximizing the gains of TT activities, TTOs set up alliances with the aim of disseminating the research results more widely and at a higher speed. The TT process is considered as interactive and multidirectional (Matt \& Schaeffer, 2012).

Tseng and Raudensky (2014) have developed the overall performance metric (OPM) as a combination of the TTO revenue and the numbers of licenses agreed, start-ups launched, 
patents issued, disclosures submitted, and patent applications filed, associated with different weighting factors (Tseng \& Raudensky, 2014).

Bigliardi and colleagues (2015) have developed a relevant framework of five main TTO performance factors: patents, licensing, license income, contracted and sponsored research to industry, and invention. According to their study, the following factors affect the TTO's economic performance: TTO's financial resources, technology brokers, skills and expertise of TTO's human recourses, contracts customization, TTO's entrepreneurial propensity, relationship with departments; degree of autonomy; TTO's age; size of the TTO; geographical proximity; size and sector of the business; firm's spontaneous demands; R\&D department budget; spin-off; brand and reputation of the university; researchers' reward system; researchers' skills; and researchers' motivation (Bigliardi et al., 2015).

De-Carli and colleagues (2016) have indicated the main barriers in TTOs' efficient performance: conflicts between institutional and researcher's interests; lack of financial resources and skilled technical employees; staff turnover; a gap between the percentage of intellectual property (IP) between universities and industry; little skill and/or disinterest of the agents; lengthy internal procedures to formalize the contractual relationship; need for IA's consolidation; legislation; and the "taboo" perception of profit by the university. On the other hand, researchers have analysed the main factors that stimulate TT, including location and commercial applicability of development research stimulate the TT, and training and qualification programmes, which are essential for TT (De-Carli et al., 2016).

Caldera and Debande (2010) have investigated the performance of HEIs in the transfer of technology in Spain. The research findings allowing to state that HEIs with their established policies and procedures for the management of TT have better economic performance results. Universities (or HEIs) with large and experienced TTOs are generating higher volumes of contract research. Furthermore, HEIs with a science park are performing better, and the agglomeration of knowledge close to universities has a positive effect on HEIs TT economic performance (Caldera \& Debande, 2010).

The external factors affecting the degree of TTOs' efficiency were investigated by Wolszczak-Derlacz (2017). US and European HEIs' TTOs were compared according to institutional settings (size and department composition), location, and funding structure. Specifically, the results have indicate a positive association between both regional GDP per capita, the number of departments and an institution's efficiency (for both the European and U.S. samples) (Wolszczak-Derlacz, 2017).

Hewitt-Dundas (2012) have demonstrated that HEIs approach to knowledge transfer was shaped by institutional and organisational resources, in particular, their ethos and research quality, rather than the capability to undertake knowledge transfer through a TTO. Strategic priorities for knowledge transfer are reflected on activity, in terms of the dominance of specific knowledge transfer channels, the partners with which universities engage, and the geography of business engagement (Hewitt-Dundas, 2012).

De Beer and colleagues (2017) indicated in their research that TTOs learn through experimentation and failure, as well as by sharing these experiences with others. They improved the rigor of the Maturity Model (MM) and formalized its application as a mechanism for sharing best practices between TTOs (De Beer et al., 2017).

Knowing how to measure the performance of TTO, how to manage the process of TT, and the main drivers of performance may help policymakers and university managers to reflect on their strategies, mitigate weak points, and thus foster TTO economic performance. 


\section{Methodological approach}

This paper is presenting the model for the integrated assessment of TT process economic performance of HEIs. The model supports a systematic procedure to assess the TTO's economic performance. In the previous section, it has already been mentioned that there has recently been observed a growing influence of many surrounding factors on the results of TTOs' economic performance, which have been included into the proposed model constructed on Multimoora multi-criteria decision-making tool.

The Multi-Objective Optimization by Ratio Analysis (MOORA) method was introduced by Brauers and Zavadskas (2006). This method was extended (Brauers, Zavadskas 2010) and became MULTIMOORA (MOORA plus the full multiplicative form). The MOORA method consists of these two parts: reference point approach and the ratio system. The MULTIMOORA method includes one more aspect as internal normalization and values all objectives as equally significant (Tian, Wang, Wang \& Zhang, 2017). Hence, MULTIMOORA calculation is composed of these three parts: ratio system, full multiplicative form and approach of reference point. Thus, MULTIMOORA is one of the most robust system of multiple objectives optimization, served to conduct robust evaluation of HEIs treatment alternatives. MULTIMOORA method is an effective tool in solving the economic problems under uncertain and incomplete information platform (Liu, You, Lu \& Chen, 2015). Both methods have been applied in a number of studies (Brauers \& Zavadskas, 2010; Eraslan \& Atalay, 2014; Lazauskas, Zavadskas \& Šaparauskas, 2015; Souzangarzadeh, Rezvani \& Jahan, 2017; Stanujkic, 2015; Ghorabaee, Zavadskas, Amiri, \& Turskis, 2016; Erdogan, Šaparauskas \& Turskis, 2017; Stanujkic et al., 2017; Stević et al., 2017; Zavadskas et al., 2017).

Brauers \& Zavadskas (2006) was developed a relevant framework for the MOORA method and introduced a system of relationships, where each response to an objective alternative is compared to a denominator, which is representative of all alternatives relating to this objective.

The MOORA method is presented by the matrix $X$, where its elements $x_{i j}$ denote $j$-th alternative of $i$-th objective $(i=1,2, \ldots \mathrm{n}$ and $j=1,2, \ldots \mathrm{m})$. In our case, we have $m=7$ alternatives (Lithuanian universities), and $n=11$ objectives (indicators). The reference point approach and the ratio system are the two elements of the MOORA method.

The first element of the ratio system defines data normalization and compares the alternative of an objective to all values of the objective:

$$
x_{i j}^{*}=\frac{x_{i j}}{\sqrt{\sum_{j=1}^{m} x_{i j}^{2}} .}
$$

Here, $x *_{i j}-$ a dimensionless number representing the normalized response of alternative $j$ on objective $i ; x_{i j}=$ response of alternative $j$ on objective $i ; j=1,2, \ldots, m ; m-$ a number of alternatives; $i=1,2, \ldots n ; n-\mathrm{a}$ number of objectives. These responses of the alternatives on the objectives belong to the interval $[0 ; 1]$.

These indicators are added (if the desirable value is maximal) or deducted (if the desirable value is minimal), and the final index is derived according to the formula:

$$
y_{j}^{*}=\sum_{i=1}^{i=g} x_{i j}^{*}-\sum_{i=g+1}^{i=n} x_{i j}^{*}
$$


Here, $y^{*}$ - the normalized assessment of alternative $j$ with respect to all objectives; $i=$ $1,2, \ldots g$, as the objectives to be maximized; $i=g+1, g+2, \ldots n$, as the objectives to be minimized.

As the starting point for the implementation of the theory, the already normalized coefficients determined by the MOORA method are used. The reference point of the $j$-th coordinate can be described as $r_{j}=\max x_{i j}{ }^{*}$ maximization case. Each coordinate of this vector is the maximum or minimum of a specific objective. Then, each element of the normalized response matrix is recalculated, and the final rank is given by the deviation from the reference point and the Min-Max Metric of Tchebycheff:

$$
\min _{i}\left(\max _{j}\left|r_{j}-x_{i j}^{*}\right|\right)
$$

The MOORA method was updated by Brauers and Zavadskas (2010) and supplemented with the Full Multiplicative Form Method, embodying maximization as well as minimization of the purely multiplicative utility function. The overall utility of the $j$-th alternative can be expressed as a dimensionless number:

$$
\begin{gathered}
U_{j}^{\prime}=\frac{A_{j}}{B_{j}}, \\
A_{j}=\prod_{g=1}^{i} x_{g i}, j=1,2, \ldots m ; m \text { - a number of alternatives; } i \text { - a number of } \\
\text { where } B_{j}=\prod_{k=i+1}^{n} x_{k j}, n \text {-i number of objectives to be minimized - utility }
\end{gathered}
$$
of alternative $j$ with objectives to be maximized and objectives to be minimized.

The MOORA and MULTIMOORA are widely applied in economic issues. For instance, the economy of regions and regional development issues are analyzed. Thus, economic ranking of European Union member states is performed, or selection of staff, as well as calculations of sustainability assessment, financial and economic development or evaluation of energy savings in buildings (Zavadskas, Antucheviciene, Saparauskas \& Turskis, 2013; Siksnelyte, Zavadskas, Bausys \& Streimikiene, 2019; Li, 2018).

One of advantage of MOORA and MULTIMOORA is making possible to avoid subjectivity, as they do not requiring the determination of the coefficients (weights) of the variables in question. Another advantage: the relationship system allows data to normalize and unify the different measurement systems; therefore, the external normalization mechanism is unnecessary. MULTIMOORA is the most robust system of optimization of multiple objectives; and this is the biggest advantage of this instrument (Brauers \& Zavadskas, 2010). The method fits to evaluate alternatives and to select the best decisions in economic, technology or management problems by using a single approach (Zavadskas, Antucheviciene, Hajiagha, Hossein, \& Hashemi, 2015).

Thus, MULTIMOORA (method of multiple objectives) tool satisfies the following conditions (Brauers \& Zavadskas, 2010):

1) In comparison with other methods MULTIMOORA is more robust involving all stakeholders (including consumer sovereignty) interested in a certain issue as an advantage.

2) MULTIMOORA with all non-correlated objectives is more robust than with limited number of objectives.

3) MULTIMOORA is more robust relating with the reason when all interrelations between alternatives and objectives are taken into consideration at the same time in comparison with interrelations only investigated two by two. 
4) MULTIMOORA is non-subjective and more robust in comparison with methods using subjective estimations to do the choice for normalization and importance of the objectives.

\section{The choice of the objectives}

A set of robust objectives could be found after session of brain storming with all the stakeholders involved or with representative experts.

\section{Normalization}

MILTIMOORA does not need external normalization and more robust than based on subjective external normalization. This method of multiple objectives uses non-subjective dimensionless measures without normalization and become more robust than other methods which use subjective non-additive scores or subjective weights.

Giving importance to an objective

Together with weights and scores, the importance of objectives is just mixed with normalization.

5) MULTIMOORA is based on cardinal numbers and is more robust than other method based on ordinal numbers.

6) MULTIMOORA with the last available data is a base for more robust research works than based on earlier data.

7) The use of two methods of multi-objective optimization is more robust than applying a single method; while the use of three methods is more robust than applying two methods, etc.

The major limit of this method is the data of objectives used, which could not be equal to zero.

\section{Conducting research and results}

\subsection{Framework of evaluation of TTO's performance in HEIs}

TTO's performance assessment model was designed based on the official public data of the Research Council of Lithuania, intended to evaluate Lithuanian universities by science business performance results. The sample period was selected from January 2012 till December 2014 , and was constrained by data availability and the desire to have the same methodological coverage of the evaluation of scientific results of Lithuanian HEIs. Later on, the Research Council of Lithuania was changed the methodology and the evaluation period (of two years: 2015 and 2016; 2017 and 2018) to assess Lithuanian HEIs. It may affect the future results. Therefore, the future research papers will analyse HEIs on the data, calculated by another methodology and time period, as 2015 and 2016.

The TTO performance assessment model includes the following TT performance indicators of HEIs: $S_{i}(T P P)$ - the amount of financial resources received by HEI during participation in international research projects of international programs ; $S_{i}(U S U)$ - the amount of financial resources received by HEI during implementation of basic, applied and experimental (social, cultural) research works with industry; $P L E_{i}$ - full-time equivalent (FTE) of university researchers; $\Sigma E V V$ - amount of points of the $1^{\text {st }}$ level research (art) works; $\Sigma A I V$ - the amount of points of the $2^{\text {nd }}$ level research (art) works; $d_{s i}$ - declared number of research works in the certain field; $F_{i}$ - formal valuation results; $E_{i}$ - normalized summed results of research works in a certain field; $S E_{i}$ - the summed measure of evaluation of experimental research works; $L E_{i}$ - normalized summed measure of research works in a certain field for each HEI, which had provided at least 5 or more experimental research works; $T_{i}$ - the number of points attributable to full-time equivalent (FTE) of one researcher; and $L F_{i}$ - measure of formal valuation, for each HEI with the full-time equivalent (FTE) equals or more than 5. 
Based on the literature review, MULTIMOORA approach was selected to design the model for the evaluation of TTO economic performance. The model presents the relationship of 11 combined indicators (Table 1). The final results of the calculation are presented in the section of results and discussion.

\subsection{Results and discussion}

This section presents the results of the application of the proposed model and provides the evaluation of the TT performance of 7 Lithuanian HEIs, which were chosen as the most active in TT activities and have sufficient results in that sphere (in comparison with other Lithuanian HEIs).

Table 1. The results of technology transfer performance indicators of Lithuanian HEIs in the fields of Humanitarian Sciences (H), Social Sciences (S), and Arts (M) for the period of 20122014

University Years

$\begin{array}{lllllllllll}(\Sigma \mathrm{EVV}) & (\mathrm{Si}(\mathrm{TPP}) & (\mathrm{Si}(\mathrm{USU})) & (\Sigma \mathrm{AIV}) & (\mathrm{dsi}) & (\mathrm{SEi}) & (\mathrm{Ei}) & (\mathrm{Ti}) & (\mathrm{Fi}) & (\mathrm{LFi}) & (\mathrm{PLEi})\end{array}$

\begin{tabular}{|c|c|c|c|c|c|c|c|c|c|c|c|c|}
\hline & & \multicolumn{11}{|c|}{ Optimization directions } \\
\hline & & Max & Max & Max & Max & Max & Max & Max & Max & Max & Max & Min \\
\hline \multirow{3}{*}{ UNI 1} & 2012 & 6.25 & 53.50 & 40.00 & 130.16 & 6.00 & 1.04 & 41.67 & 12.66 & 19.04 & 43.00 & 10.28 \\
\hline & 2013 & 9.00 & 82.30 & 20.00 & 119.74 & 6.00 & 1.50 & 62.50 & 16.48 & 43.37 & 28.92 & 10.20 \\
\hline & 2014 & 13.25 & 247.54 & 8.60 & 175.16 & 7.00 & 1.89 & 75.71 & 16.59 & 29.98 & 25.40 & 12.13 \\
\hline \multirow{3}{*}{ UNI 2} & 2012 & 84.00 & 742.37 & 28.00 & 1252.04 & 54.00 & 4.68 & 169.18 & 45.68 & 131.76 & 166.81 & 73.78 \\
\hline & 2013 & 113.50 & 253.13 & 93.85 & 1592.85 & 74.00 & 4.74 & 174.17 & 49.32 & 164.30 & 164.30 & 102.51 \\
\hline & 2014 & 103.25 & 298.43 & 187.01 & 1407.86 & 66.00 & 4.61 & 165.60 & 55.45 & 149.15 & 149.15 & 94.16 \\
\hline \multirow{3}{*}{ UNI 3} & 2012 & 88.25 & 113.51 & 933.13 & 1812.68 & 54.00 & 5.25 & 189.57 & 55.59 & 157.00 & 203.08 & 96.79 \\
\hline & 2013 & 99.25 & 82.65 & 214.57 & 1787.95 & 77.00 & 3.91 & 148.87 & 60.03 & 204.26 & 204.26 & 88.52 \\
\hline & 2014 & 143.25 & 0.00 & 757.55 & 1299.01 & 79.00 & 5.10 & 183.85 & 42.85 & 142.90 & 142.90 & 95.94 \\
\hline \multirow{3}{*}{ UNI 4} & 2012 & 1.00 & 0.00 & 0.00 & 24.36 & 3.00 & 0.20 & 8.00 & 8.45 & 19.76 & 0.00 & 6.20 \\
\hline & 2013 & 2.50 & 0.00 & 0.00 & 101.80 & 3.00 & 1.50 & 63.89 & 22.99 & 58.54 & 0.00 & 7.92 \\
\hline & 2014 & 1.75 & 0.00 & 0.00 & 67.27 & 3.00 & 0.58 & 23.33 & 15.70 & 32.44 & 0.00 & 8.25 \\
\hline \multirow{3}{*}{ UNI 5} & 2012 & 112.25 & 0.00 & 25.00 & 3280.42 & 76.00 & 2.11 & 84.86 & 44.15 & 86.99 & 140.16 & 126.59 \\
\hline & 2013 & 90.75 & 35.31 & 76.22 & 4194.67 & 68.00 & 1.79 & 74.92 & 58.19 & 153.83 & 153.83 & 113.50 \\
\hline & 2014 & 120.50 & 33.06 & 278.52 & 2297.03 & 75.00 & 2.55 & 105.98 & 29.49 & 58.43 & 58.43 & 125.68 \\
\hline \multirow{3}{*}{ UNI 6} & 2012 & 59.25 & 320.78 & 199.25 & 742.03 & 33.00 & 5.01 & 174.05 & 55.27 & 175.45 & 203.10 & 43.77 \\
\hline & 2013 & 50.50 & 163.57 & 28.37 & 673.21 & 33.00 & 4.05 & 139.02 & 49.38 & 174.02 & 174.02 & 43.39 \\
\hline & 2014 & 63.00 & 216.49 & 10.00 & 748.99 & 35.00 & 4.61 & 157.21 & 54.36 & 159.64 & 159.64 & 43.04 \\
\hline \multirow{3}{*}{ UNI 7} & 2012 & 240.75 & 79.73 & 407.74 & 4422.67 & 122.00 & 3.94 & 159.28 & 43.31 & 93.00 & 133.85 & 204.26 \\
\hline & 2013 & 239.50 & 1032.69 & 300.80 & 3952.50 & 125.00 & 3.83 & 164.79 & 38.09 & 108.78 & 108.78 & 208.61 \\
\hline & 2014 & 264.25 & 215.09 & 1114.44 & 4931.32 & 126.00 & 4.20 & 179.22 & 46.59 & 99.28 & 99.28 & 211.70 \\
\hline
\end{tabular}

Source: own compilation 
Table 3 shows the relations system values and reference points values of all indicators ( $S_{i}(U S U), S_{i}(T P P), \Sigma E V V, \Sigma A I V, d_{s i}, S E_{i}, E_{i}, T_{i}, F_{i}, L F_{i}, P L E_{i}$ ) for the period of 2012-2014. The results showed that UNI 7, UNI 2, and UNI 3 have the greatest economic performance results among other Lithuanian HEIs in the sample, implementing research and innovation activities in the fields of $\mathrm{H}, \mathrm{S}, \mathrm{M}, \mathrm{P}, \mathrm{A}, \mathrm{B}$ ), and T sciences. The ranking of HEIs by the final value of full multiplication form highlighted the next HEIs: UNI 7, UNI 2, and UNI 6, having the highest economic performance results. That means they are the most entrepreneurial and have much better-developed innovation and TT systems inside HEIs, as well as quite good allocation system of financial and human resources. Furthermore, we can state that UNI 7, UNI 2, and UNI 6 have much better motivation systems for TTO staff, and they are more experienced bringing better commercialization results.

Going deeper into the category of $\mathrm{H}, \mathrm{S}$, and $\mathrm{M}$ of separate indicators (see Table 1) and its results, we can demonstrate that in 2012 the highest economic income of the indicator $\left(S_{i}(T P P)\right.$ ), showing the economic results of research projects (international programmes), had UNI 2, UNI 6, and UNI 3. Meanwhile, in 2013 the greatest results of this indicator showed UNI 7, UNI 2 and UNI 6. Therefore, in 2014 UNI 2, UNI 1, and UNI 6 had the best economic performance results. After the deeper economic analysis of another indicator - $S_{i}(U S U)$, meaning the performance of industry-academic cooperation results, we can state that the most significant part of all greatest results belongs to the UNI 3, UNI 7, and UNI 6 in 2012. The rest universities' had bigger income gap by ten times, and it means that those HEIs have the worst developed TT and commercialization system inside HEIs, and need the improvement to fosted organizations' economic performance. Therefore, we see that the results of $S_{i}(U S U)$ every year are different, except of UNI 7 (generally the leader of all analysed TT performance indicators in this paper). Other universities in 2013 and 2014 had the gap of income less than ten times. In addition, we see the clear tendency that every year the economic results of HEIs of $S_{i}(U S U)$ is increasing, especially of HEIs with the lowest results, $e . g$. UNI 2.. If we analyse the fulltime equivalent $(F T E)$ indicator, we clearly see the relation between the number of academic staff and TTO performance results at HEIs. Therefore, the efficient use of human resources improve overall economic results of universities. UNI 7 is the leader of the $P L E_{i}$ indicator, and its result about twice greater than any other university in the research sample. The $P L E_{i}$ indicator also interrelated with economic indicators as $\Sigma E V V$ and $\Sigma A I V$, due to the fact that the points attributed for these indicators was calculated based on the research results of HEIs. The more research staff, the more research results could be prepared converted to publications, projects, order based works and similar. All other economic results also related to the number of academic staff in FTE $\left(P L E_{i}\right)$.Universities economic performance results in the fields of $\mathrm{P}$, $\mathrm{A}, \mathrm{B}$, and $\mathrm{T}$ are presented below (Table 2). 
Table 2. The results of technology transfer performance indicators of Lithuanian HEIs in the fields of physical sciences (P), agricultural sciences (A), biomedical sciences (B), technological sciences (T) for the period of 2012-2014

\begin{tabular}{|c|c|c|c|c|c|c|c|c|c|c|c|c|}
\hline \multirow{3}{*}{ University } & e & $\begin{array}{c}(\Sigma \\
\text { EVV) }\end{array}$ & $\begin{array}{c}(\mathbf{S i} \\
(\mathbf{T P P}))\end{array}$ & $\begin{array}{c}(\mathbf{S i} \\
(\mathbf{U S U}))\end{array}$ & $(\Sigma \mathrm{AIV})$ & (ds i) & (SE i) & (Ei) & (Ti) & (Fi) & (LFi) & (PLEi) \\
\hline & & \multicolumn{11}{|c|}{ Optimization directions } \\
\hline & & Max & Max & Max & Max & Max & Max & Max & Max & Max & Max & Min \\
\hline \multirow{3}{*}{ UNI 1} & 2012 & 44.50 & 523.58 & 622.83 & 131.62 & 19.00 & 7.48 & 196.77 & 5.95 & 90.74 & 125.77 & 57.18 \\
\hline & 2013 & 42.50 & 457.15 & 360.63 & 300.37 & 17.00 & 7.50 & 188.00 & 11.77 & 168.30 & 194.96 & 73.03 \\
\hline & 2014 & 41.50 & 641.30 & 803.88 & 219.20 & 18.00 & 6.94 & 175.59 & 8.96 & 149.92 & 199.65 & 74.78 \\
\hline \multirow{3}{*}{ UNI 2} & 2012 & 137.50 & 5035.90 & 2585.61 & 802.84 & 51.00 & 8.67 & 228.73 & 18.59 & 145.48 & 122.17 & 232.13 \\
\hline & 2013 & 125.00 & 6249.98 & 5120.68 & 1091.18 & 48.00 & 7.96 & 197.99 & 23.26 & 248.13 & 148.13 & 216.67 \\
\hline & 2014 & 152.00 & 5008.24 & 1811.79 & 1092.99 & 45.00 & 9.32 & 231.84 & 29.87 & 254.96 & 154.96 & 205.12 \\
\hline \multirow{3}{*}{ UNI 3} & 2012 & 40.00 & 1243.20 & 102.14 & 169.71 & 17.00 & 7.15 & 188.57 & 6.34 & 36.69 & 126.07 & 83.19 \\
\hline & 2013 & 26.00 & 263.84 & 213.41 & 100.43 & 15.00 & 5.20 & 126.54 & 5.21 & 54.86 & 82.73 & 53.65 \\
\hline & 2014 & 39.50 & 784.59 & 224.76 & 224.52 & 16.00 & 7.20 & 179.47 & 10.79 & 107.88 & 181.48 & 66.74 \\
\hline \multirow{3}{*}{ UNI 4} & 2012 & 177.50 & 1110.77 & 842.47 & 708.33 & 56.00 & 8.43 & 178.05 & 6.71 & 64.62 & 137.67 & 218.47 \\
\hline & 2013 & 198.00 & 937.20 & 955.13 & 776.40 & 58.00 & 9.37 & 238.52 & 12.24 & 158.37 & 188.06 & 273.35 \\
\hline & 2014 & 227.50 & 678.43 & 425.98 & 988.45 & 59.00 & 10.80 & 273.31 & 11.36 & 141.99 & 204.67 & 279.99 \\
\hline \multirow{3}{*}{ UNI 5} & 2012 & 9.00 & 0.00 & 0.00 & 7.25 & 15.00 & 1.80 & 21.62 & 0.87 & 1.14 & 13.13 & 15.92 \\
\hline & 2013 & 10.50 & 0.00 & 0.00 & 12.24 & 5.00 & 2.10 & 54.19 & 1.69 & 22.61 & 22.61 & 13.67 \\
\hline & 2014 & 34.00 & 0.00 & 19.36 & 45.17 & 15.00 & 6.80 & 168.80 & 19.20 & 130.42 & 46.17 & 12.34 \\
\hline \multirow{3}{*}{ UNI 6} & 2012 & 89.00 & 792.08 & 3912.71 & 458.33 & 43.00 & 4.69 & 53.70 & 5.99 & 33.08 & 88.14 & 208.59 \\
\hline & 2013 & 114.00 & 161.79 & 2405.36 & 840.90 & 41.00 & 5.66 & 67.41 & 9.41 & 121.32 & 121.32 & 200.66 \\
\hline & 2014 & 127.00 & 190.44 & 932.24 & 732.67 & 40.00 & 6.71 & 166.59 & 8.11 & 116.96 & 116.96 & 198.16 \\
\hline \multirow{3}{*}{ UNI 7} & 2012 & 397.00 & 4099.63 & 2197.96 & 2981.26 & 104.00 & 11.20 & 196.40 & 17.16 & 141.11 & 280.27 & 522.72 \\
\hline & 2013 & 414.50 & 3762.37 & 2204.80 & 2755.54 & 108.00 & 11.69 & 188.33 & 20.25 & 270.18 & 223.02 & 543.75 \\
\hline & 2014 & 429.50 & 2335.23 & 1656.09 & 3350.85 & 107.00 & 11.98 & 298.05 & 17.44 & 218.79 & 274.21 & 533.13 \\
\hline
\end{tabular}

Source: own compilation

Comparing economic performance results in the fields of $\mathrm{H}, \mathrm{S}$, and $\mathrm{M}$, the similar tendencies are noticeable with TT performance results in other fields of $\mathrm{P}, \mathrm{A}, \mathrm{B}, \mathrm{T}$ in the period of 20122014. The next table 3 is presented the final calculations incorporating the economic performance results in TT activities in all fields in the sample for the period of 2012-2014. 
Table 3. The final results of HEIs technology transfer economic performance based on MULTIMOORA tool for the period of 2012-2014

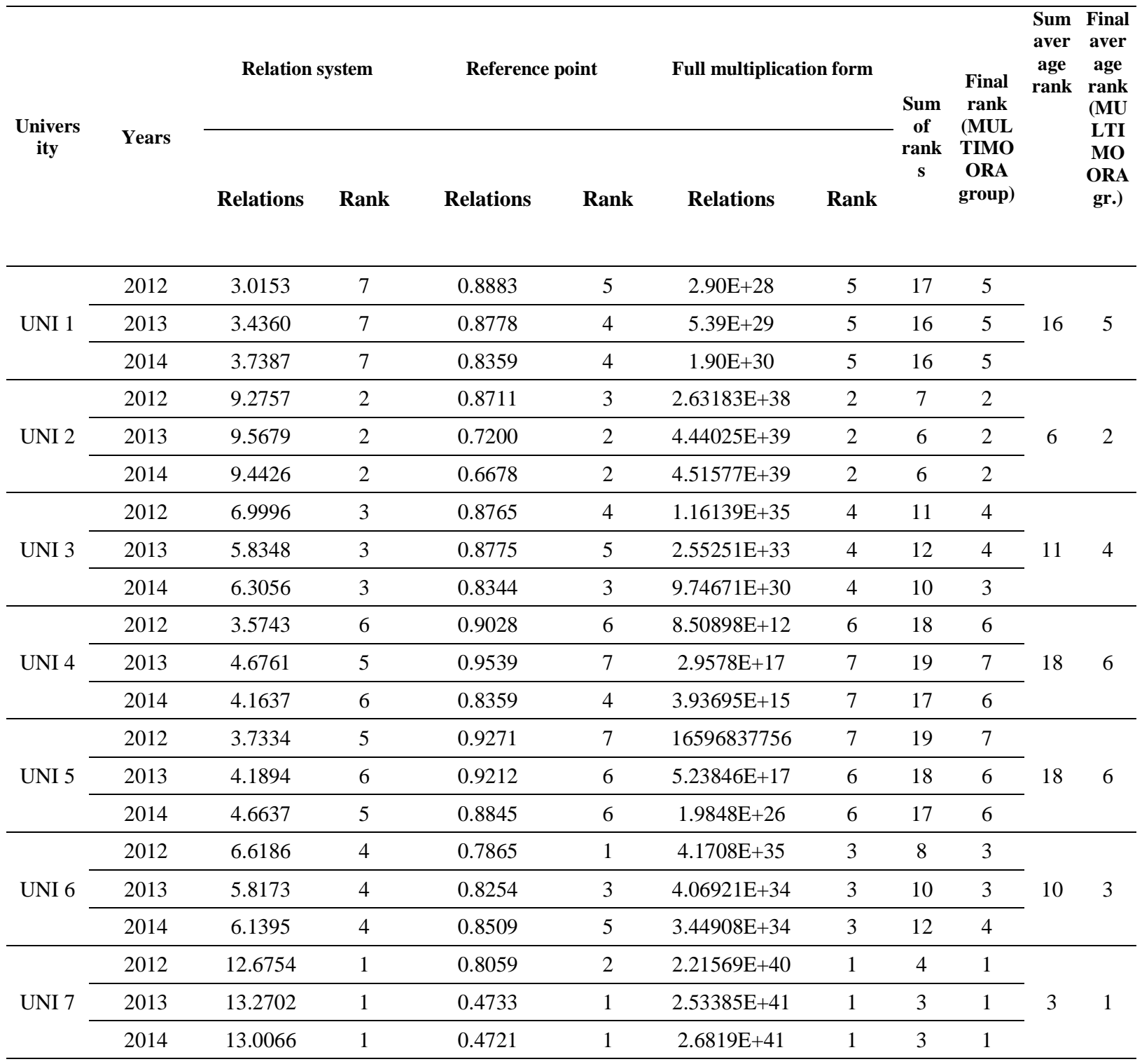

Source: own compilation

The final distribution of TT economic performance results are presented in Table 3. Therefore, we see that the greatest TT performance results have UNI 7, UNI 2 and UNI 6. The research results showed the dependency of FTE and the research and innovation results (converted in publications, projects, order based works and similar) with HEIs economic performance results.

The research results reflect that MULTIMOORA multi-criteria evaluation tool is nonsubjective and makes possible to systematize information and make impartial conclusions about the efficiency of universities. The complexity increases with increasing choices of alternatives and features, therefore MULTIMOORA is useful in selecting the best alternatives. Latter method serves for efficient allocation of financial and human resources. TT process economic performance results of universities allow decision makers to evaluate current situation and make decisions on the future improvement of financial and human capital allocation. Taking into account necessary factors, influencing TT process economic performance, universities' heads could improve internal TT policy, strategy, reorient universities financial and human 
resources priorities to reach new goals, helping to improve overall HEI's economic performance. MULTIMOORA tool is based on mathematical calculations for evaluation of TT process economic performance.

\section{Conclusion}

The purpose of this paper was to broaden existing theory on the assessment of the economic performance of the TT process at HEIs with a particular focus on the value creation by TTOs inside HEIs. The performance results of TT indicators depend on the successful work and experience of TTOs at HEIs, and on the self-motivation of HEIs academics, who are working closely with industry (related to the clear and beneficial motivation system of HEIs and the wellbeing inside HEI). After exploring the main drivers of value creation in the TT process and the main indicators of TTO economic performance results, the findings allowed to expand understanding of TT directions and possibilities to maximize the of efficiency of economic performance results.

In the methodological aspect, the research paper extended the application of MULTIMOORA possibilities and applied it in the evaluation of TT in the context of higher education economic performance. MULTIMOORA serves for efficient allocation of financial and human resources, and allow decision makers to evaluate the current situation and make decisions on the future improvement of financial and human capital allocation. In this way, HEIs heads could improve internal TT policy, strategy, and reorient HEIs financial and human resources for priorities to reach new goals, helping to improve overall efficiency of HEI's economic performance.

However, this work has its limitations. Our study was conducted evaluating Lithuanian HEIs, and the findings may, therefore, not apply to countries that are more advanced in the TT process and have higher rankings by the global innovation index. Second, our data sample was selected in the period of 2012-2014, and it is the only one official public data available for periodically analysis of Lithuanian HEIs. Third, the evaluation of the TT performance of the seven Lithuanian HEIs, which have the sufficient results of TT activities, is provided in this paper. For further research, we suggest to increase the sample of HEIs according to TT economic performance results.

The main issue for every university is to find the proper tool to evaluate the TT economic performance of HEIs, to make insights and to increase the economic efficiency. We expect that future work will extend the indicators to measure the efficiency of TT process economic performance. Furthermore, additional assessment of TTOs' economic value and cost optimization of TT process are options for the future research.

\section{References}

Ab Hamid, M. R. B. (2015). Value-based performance excellence model for higher education institutions. Quality \& Quantity, 49(5), 1919-1944.

Argote, L., \& Ingram, P. (2000). Knowledge transfer: A basis for competitive advantage in firms. Organizational behavior and human decision processes, 82(1), 150-169.

Asif, M., \& Searcy, C. (2014). Determining the key capabilities required for performance excellence in higher education. Total Quality Management \& Business Excellence, 25(12), 22-35.

Baek, D. H., Sul, W., Hong, K. P., \& Kim, H. (2007). A technology valuation model to support technology transfer negotiations. R\&D Management, 37(2), 123-138.

Bercovitz, J., \& Feldman, M. (2006). Entpreprenerial universities and technology transfer: A conceptual framework for understanding knowledge-based economic development. The 
Journal of Technology Transfer, 31(1), 175-188.

Bigliardi, B., Galati, F., Marolla, G., \& Verbano, C. (2015). Factors affecting technology transfer offices' performance in the Italian food context. Technology Analysis \& Strategic Management, 27(4), 361-384.

Bini, L., Dainelli, F., \& Giunta, F. (2016). Business model disclosure in the strategic report: entangling intellectual capital in value creation process. Journal of Intellectual Capital, 17(1), 83-102.

Brauers, W. K. M., \& Zavadskas, E. K. (2010). Project management by MULTIMOORA as an instrument for transition economies. Technological and Economic Development of Economy, 16(1), 5-24.

Caldera, A., \& Debande, O. (2010). Performance of Spanish universities in technology transfer: An empirical analysis. Research Policy, 39(9), 1160-1173.

Cao, Y., Zhao, L., \& Chen, R. (2009). Institutional structure and incentives of technology transfer: Some new evidence from Chinese universities. Journal of technology management in China, 4(1), 67-84.

Cattaneo, M., Meoli, M., \& Signori, A. (2016). Performance-based funding and university research productivity: the moderating effect of university legitimacy. The Journal of Technology Transfer, 41(1), 85-104.

Chapple, W., Lockett, A., Siegel, D., \& Wright, M. (2005). Assessing the relative performance of UK university technology transfer offices: parametric and non-parametric evidence. Research Policy, 34(3), 369-384.

Closs, L., Cardozo Ferreira, G., Freitas Soria, A., Hoffmann Sampaio, C., \& Perin, M. (2012). Organizational factors that affect the university-industry technology transfer processes of a private university. Journal of technology management \& innovation, 7(1), 104-117.

Collier, A. (2007). Australian framework for the commercialisation of university scientific research. Prometheus, 25(1), 51-68.

Conti, A., \& Gaule, P. (2011). Is the US outperforming Europe in university technology licensing? A new perspective on the European Paradox. Research Policy, 40(1), 123-135.

Curi, C., Daraio, C., \& Llerena, P. (2015). The productivity of French technology transfer offices after government reforms. Applied Economics, 47(28), 3008-3019.

De-Carli, E., Ferasso, M., Segatto, A., \& Alves, F. (2016). The Dilemma of Industry-University Cooperation Processes within Technology Transfer Offices: Evidence from Three Brazilian Case Studies.

De Beer, C., Secundo, G., Passiante, G., \& Schutte, C. S. (2017). A mechanism for sharing best practices between university technology transfer offices. Knowledge Management Research \& Practice, 15(4), 523-532.

Decter, M., Bennett, D., \& Leseure, M. (2007). University to business technology transfer-UK and USA comparisons. Technovation, 27(3), 145-155.

Eraslan, E., \& Atalay, K. D. (2014). A comparative holistic fuzzy approach for evaluation of the chain performance of suppliers. Journal of Applied Mathematics, 2014.

Erdogan, S. A., Šaparauskas, J., \& Turskis, Z. (2017). Decision making in construction management: AHP and expert choice approach. Procedia engineering, 172, 270-276.

Feng, H. I., Chen, C. S., Wang, C. H., \& Chiang, H. C. (2012). The role of intellectual capital and university technology transfer offices in university-based technology transfer. The Service Industries Journal, 32(6), 899-917.

Franklin, S. J., Wright, M., \& Lockett, A. (2001). Academic and surrogate entrepreneurs in university spin-out companies. The Journal of Technology Transfer, 26(1-2), 127-141.

Ghorabaee, M. K., Zavadskas, E. K., Amiri, M., \& Turskis, Z. (2016). Extended EDAS method for fuzzy multi-criteria decision-making: an application to supplier selection. International journal of computers communications \& control, 11(3), 358-371. 
Guerrero, M., Cunningham, J. A., \& Urbano, D. (2015). Economic impact of entrepreneurial universities' activities: An exploratory study of the United Kingdom. Research Policy, 44(3), 748-764.

Guerrero, M., Urbano, D., \& Fayolle, A. (2016). Entrepreneurial activity and regional competitiveness: evidence from European entrepreneurial universities. The Journal of Technology Transfer, 41(1), 105-131.

Hewitt-Dundas, N. (2012). Research intensity and knowledge transfer activity in UK universities. Research policy, 41(2), 262-275.

Hsu, D. W., Shen, Y. C., Yuan, B. J., \& Chou, C. J. (2015). Toward successful commercialization of university technology: Performance drivers of university technology transfer in Taiwan. Technological Forecasting and Social Change, 92, 25-39.

Hülsbeck, M., Lehmann, E. E., \& Starnecker, A. (2013). Performance of technology transfer offices in Germany. The journal of technology transfer, 38(3), 199-215.

Lafuente, E., \& Berbegal-Mirabent, J. (2017). Assessing the productivity of technology transfer offices: An analysis of the relevance of aspiration performance and portfolio complexity. The Journal of Technology Transfer, 1-24.

Lazauskas, M., Zavadskas, E. K., \& Šaparauskas, J. (2015). Ranking of priorities among the baltic capital cities for the development of sustainable construction. Economics and Management.

Li, C. (2018). Evaluation of the financial and economic development of the European Union member states on basis of multiple indicators changed to multiple objectives. Economics and Management.

Liu, H. C., You, J. X., Lu, C., \& Chen, Y. Z. (2015). Evaluating health-care waste treatment technologies using a hybrid multi-criteria decision making model. Renewable and Sustainable Energy Reviews, 41, 932-942.

Matt, M., \& Schaeffer, V. (2012). The cooperative strategy of technology transfer offices: A longitudinal study. In Technology transfer in a global economy (pp. 51-72). Springer, Boston, MA.

McAdam, R., Miller, K., McAdam, M., \& Teague, S. (2012). The development of University Technology Transfer stakeholder relationships at a regional level: Lessons for the future. Technovation, 32(1), 57-67.

Miller, K., McAdam, R., \& McAdam, M. (2018). A systematic literature review of university technology transfer from a quadruple helix perspective: toward a research agenda. $R \& D$ Management, 48(1), 7-24.

Nielsen, K. (2015). Human capital and new venture performance: the industry choice and performance of academic entrepreneurs. The Journal of Technology Transfer, 40(3), 453474.

Oehler, A., Höfer, A., \& Schalkowski, H. (2015). Entrepreneurial education and knowledge: Empirical evidence on a sample of German undergraduate students. The Journal of Technology Transfer, 40(3), 536-557.

Pastor, J. M., Serrano, L., \& Zaera, I. (2015). The research output of European higher education institutions. Scientometrics, 102(3), 1867-1893.

Rademakers, M. (2005). Corporate universities: driving force of knowledge innovation. Journal of workplace Learning, 17(1/2), 130-136.

Rossi, F., \& Rosli, A. (2015). Indicators of university-industry knowledge transfer performance and their implications for universities: evidence from the United Kingdom. Studies in Higher Education, 40(10), 1970-1991.

Sharifi, H., Liu, W., \& Ismail, H. S. (2014). Higher education system and the 'open'knowledge transfer: a view from perception of senior managers at university knowledge transfer offices. Studies in Higher Education, 39(10), 1860-1884. 
Siegel, D. S., Waldman, D., \& Link, A. (2003). Assessing the impact of organizational practices on the relative productivity of university technology transfer offices: an exploratory study. Research policy, 32(1), 27-48.

Siksnelyte, I., Zavadskas, E. K., Bausys, R., \& Streimikiene, D. (2019). Implementation of EU energy policy priorities in the Baltic Sea Region countries: Sustainability assessment based on neutrosophic MULTIMOORA method. Energy Policy, 125, 90-102.

Souzangarzadeh, H., Rezvani, M. J., \& Jahan, A. (2017). Selection of optimum design for conical segmented aluminum tubes as energy absorbers: Application of MULTIMOORA method. Applied Mathematical Modelling, 51, 546-560.

Stanujkic, D. (2016). An extension of the ratio system approach of MOORA method for group decision-making based on interval-valued triangular fuzzy numbers. Technological and Economic Development of Economy, 22(1), 122-141.

Stanujkic, D., Zavadskas, E. K., Smarandache, F., Brauers, W. K., \& Karabasevic, D. (2017). A neutrosophic extension of the MULTIMOORA method. Informatica, 28(1), 181-192.

Stević, Ž., Pamučar, D., Vasiljević, M., Stojić, G., \& Korica, S. (2017). Novel integrated multicriteria model for supplier selection: Case study construction company. Symmetry, 9(11), 279.

Tian, Z. P., Wang, J., Wang, J. Q., \& Zhang, H. Y. (2017). An improved MULTIMOORA approach for multi-criteria decision-making based on interdependent inputs of simplified neutrosophic linguistic information. Neural Computing and Applications, 28(1), 585-597.

Tseng, A. A., \& Raudensky, M. (2014). Performance evaluations of technology transfer offices of major US research universities. Journal of technology management \& innovation, 9(1), 93-102.

Wolszczak-Derlacz, J. (2017). An evaluation and explanation of (in) efficiency in higher education institutions in Europe and the US with the application of two-stage semiparametric DEA. Research Policy, 46(9), 1595-1605.

Zavadskas, E. K., Bausys, R., Juodagalviene, B., \& Garnyte-Sapranaviciene, I. (2017). Model for residential house element and material selection by neutrosophic MULTIMOORA method. Engineering Applications of Artificial Intelligence, 64, 315-324.

Zavadskas, E. K., Antucheviciene, J., Saparauskas, J., \& Turskis, Z. (2013). MCDM methods WASPAS and MULTIMOORA: verification of robustness of methods when assessing alternative solutions. Economic Computation and Economic Cybernetics Studies and Research, 47(2), 5-20.

Zavadskas, E. K., Antucheviciene, J., Hajiagha, R., Hossein, S., \& Hashemi, S. S. (2015). The interval-valued intuitionistic fuzzy MULTIMOORA method for group decision making in engineering. Mathematical Problems in Engineering, 2015.

Zhurakovska, M. B. (2013). Economic Monitoring of Technology Transfer Offices Activity. Scientific Bulletin of National Mining University, (1), 113-120. 